\title{
O Resmungar de um Professor Esgotado*
}

Sou professor de química numa das principais universidades americanas há mais de vinte e cinco anos e estou cansado. Quero dizer com isto que o quociente entre o nível de satisfação que recebo e o tempo e o esforço que invisto nos meus alunos já se deteriorou a tal ponto, que simplesmente já não sinto gozo nenhum naquilo que estou a fazer.

Tenho a impressão que existem cada vez menos alunos que sabem o que é ter curiosidade e que esta carência os impede de aceitar as inconveniências associadas à aprendizagem. Cada vez menos alunos têm perseverância para continuar um projecto de investigação quando este não dá frutos.

Acabei de corrigir os exames do meu curso de análise quantitativa e uma das perguntas - "prenda" da primeira página questionava se uma solução de acetato de sódio em água seria ácida, básica ou neutra. Sete em quatorze alunos responderam que seria ácida ou neutra e defenderam as suas respostas das formas mais bizarras. Das suas justificações tornou-se claro que eles nem sequer tinham aprendido quais eram as principais espécies existentes em tal solução. Durante o curso discutimos o uso de indicadores químicos; a cada aluno foi pedido para calcular o pH no ponto de equivalência duma titulação de amónia com ácido clorídrico de forma a escolher um indicador apropriado. Mais ainda, fizemos na aula vários problemas de soluções de ácidos fracos e bases fracas, como também falámos especificamente de hidrólise e disselhes para se lembrarem que a regra básica era um ácido forte com uma base fraca produzir sempre uma solução ácida, ou seja, o componente mais forte predomina. $E$ isto tudo veio na sequência da introdução do fenómeno de hidrólise e das suas implicações para o cálculo do $\mathrm{pH}$ no seu curso de química geral!

Depois de muita reflexão sobre tudo isto ainda não me consegui convencer que tais alunos, que ainda não conseguiram absorver conceitos básicos depois de tanta repetição, possam ter interesse algum na química.

Seria simpático se os alunos das minhas aulas de química de cursos não-científicos tivessem algum interesse pela matéria, embora consiga aceitar que não o tenham. Porém, finalistas e alunos do terceiro ano de química quero sim que tenham interesse em química! Quero que os alunos da análise quantitativa sintam alguma satisfação ao conseguirem calcular o pH duma solução. Quero também que os alunos de química geral tenham curiosidade sobre o funcionamento das coisas e que mostrem disponibilidade e se esforcem para descobrir coisas por eles mesmos. Como a inteligência humana é capaz de muito mais do que o actual sistema educacional americano exige, não consigo aceitar mais o estado das coisas.

Para o curso de Química Geral destinado aos alunos avançados, utilizo um texto para laboratórios que já não é editado, escrito por professores da universidade Oberlin College (a quem agradeço a permissão de utilizá-lo) porque o nível dos textos actualmente disponíveis é demasiadamente elementar. (A minha procura de um texto para laboratório que motivasse os alunos revelou-me que outros departamentos escrevem os seus próprios manuais de laboratórios pelos mesmos motivos). Para o meu curso de análise quantitativa, utilizo o livro de R. W. Ramette (também já fora de impressão e com igual reconhecimento da gentileza de me dar autorização de o utilizar) pois não há nada no mercado que lhe seja comparável no que diz respeito ao tratamento de coeficientes de actividade, mas igualmente na sua competência de apresentação da matéria em geral.

Porque será que os textos adequados para os alunos mais interessados e motivados para o estudo da química deixam de ser publicados? A resposta óbvia é que o mercado para tais textos é demasiadamente pequeno.

Nunca senti a mínima obrigação de tentar estimular o interesse dos alunos para a química. Se tiverem interesse. farei tudo o que puder para os ajudar a atingir os seus objectivos. Se não tiverem, porque hão-de dizer que o têm? Porque não escolher outro curso? Porque é que passam mais tempo a explicar-me a importância da obtenção de uma nota positiva, do que o que passam a estudar e a aprender a matéria e na resolução de problemas?

Será possível que as nossas universidades se estejam a encher de alunos a fazer cursos que não thes interessam? De acordo com a minha experiência, isto está a acontecer no campo da química. Faço tudo para os convencer que estari- am certamente mais contentes a fazer outra coisa e que a transferência para outro curso não significa que tivessem fracassado. Os meus conselhos são tão eficazes quanto as minhas aulas. Eles não me ouvem. Parecem ver a química somente como uma forma de ganhar a vida e os cursos como um ritual de passagem que nada tem a ver com o processo de aprendizagem. A mesma mentalidade baseia-se na ideia que pagar propinas e assistir às aulas com um mínimo de regularidade lhes garantirá uma nota positiva. Alguns têm abandonado esta ideia depois de chumbar, para logo de seguida substituí-la pela certeza de que chumbar duas vezes seria uma injustiça perante a qual o professor deveria responder em tribunal.

Para além da sua incapacidade em assimilar conceitos fundamentais de química, há outras evidências que comprovam a minha constatação de que a maioria dos meus alunos não se interessam pela disciplina: a alegria com que vendem os seus textos de química depois de terminarem a cadeira. Já lá vão os tempos em que eu ainda tentava apaziguar a minha consciência ao adoptar um texto caríssimo de química - física para o laboratório, convencido que ele representava um acréscimo valioso à biblioteca do aluno. No entanto, descobri recentemente que esta ideia era uma simples ilusão romântica, pelo que presentemente utilizo um livro de texto menos exaustivo, com capa em papel e muito menos dispendioso. Desta forma os alunos perdem menos dinheiro ao vendê-lo.

Penso que uma grande parte do problema que aqui descrevo surge de uma mentalidade educativa que os alunos viveram antes de chegar à universidade. O jornal diário local trouxe recentemente uma reportagem acerca da polémica demissão de uma professora de matemática do secundário da costa Leste que foi demitida porque demasiados estudantes reprovaram. O director da escola respondeu ao argumento da senhora de que os alunos com negativas não tinham aprendido as matérias requeridas, dizendo que o objectivo principal do ensino secundário era o de promover a auto-estima dos alunos. Apesar de se ter gerado um processo em tribunal, com o apoio de antigos alunos chumbados a declararem que mereceram a reprovação, a professora foi mesmo despedida. Segun- 
do a reportagem, ela trabalha actualmente como empregada de restaurante na terra onde outrora leccionava matemática.

Encontro-me seriamente preocupado com o facto de o ponto de vista expresso pelo director não representar uma opinião minoritária no sistema educacional deste país. Um dos alunos que perdeu "o comboio da hidrólise" na minha aula de analítica baseia a sua escolha de curso num trabalho de liceu a respeito do meio ambiente. Frequentou um liceu especial para alunos altamente bem preparados $\mathrm{e}$ tenho a total certeza de que o seu professor foi entusiástico e bem intencionado. O jovem está plenamente convencido que é um cientista em potencial e sente o seu ego aumentado, de tal forma que o nosso director da escola da costa Leste indicá-lo-ia orgulhosamente como um exemplo do tipo de aluno que as nossas escolas deveriam estar a produzir. No entanto, este aluno nunca aprendeu como estudar e, com base no seu resultado do exame de analítica, absorveu pouquíssi- mo dos conceitos a respeito de soluções aquosas. Penso que ele está genuinamente confundido com os seus fracos resultados, mas culpabiliza-me mais a mim que a si próprio.

A obrigação de lidar com alunos mal preparados para o necessário raciocínio quantitativo e conceitual que está associado à química e que não mostram sinais de estar interessados na disciplina, é uma experiência verdadeiramente deprimente. Leccionar ao nível superior foi uma opção própria, no entanto aquilo que ando a fazer nada tem a ver com a minha imagem do que deveria ser. Além do mais, considerando que os directores da minha universidade se assemelham mais a gestores de negócios do que a académicos, pouco se pode esperar relativamente a alguma melhoria no futuro próximo. Há alguns anos um colega do departamento de biologia deixou a universidade optando por um posto fora do âmbito académico, queixando-se da direcção para que o então sistema de ensino superior caminhava, com a substituição de académicos por gestores com MBA's na administração do ensino superior, e a consequente transferência do poder de decisão sobre assuntos com sérias repercusões para a capacidade dos professores em exercer as suas responsabilidades.

O meu colega tinha toda a razão e as coisas têm piorado desde então.

As nossas universidades estão-se a encher de estudantes que têm uma ideia errada acerca das razões pelas quais lá estão, e as suas opiniões têm sido apoiadas por administradores que os veêm mais como activos de um balanço comercial do que como seres pensantes.

Chegou-se ao ponto em que demasiados alunos não assumem qualquer tipo de responsibilidade, e em que um número exagerado de "educadores" profissionais dispendem demasiado tempo a analizar, a documentar, e a reestruturar e ..,

Como dizem os meus alunos quando a campaínha toca "já me vou"...

* Autor Anónimo

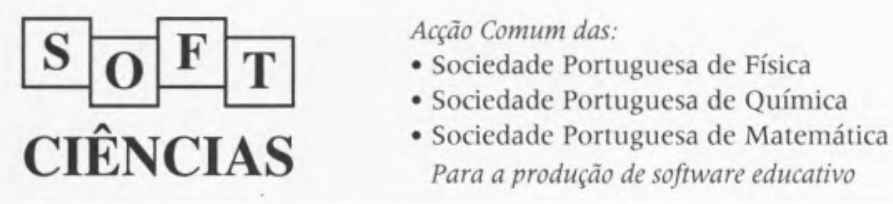

1. GALILEO

2 JOGOS QUÍMICOS

3. KEPLER

4. LECHAT

5. ÓPTICA

6. FQ-FOLHA DE CÁLCULO

7. ENERGIA

8. FRACTAIS

9. MILLIKAN

10. RELATIVO
Uma viagem espacial

Jogo das Substâncias e Adivinhas

O céu na nossa mão

Simulações em equilíbrio químico

Banco de óptica no computador

Programas em "Excel"

A gestão da energia na terra

Um mundo de imagens matemáticas

Meça a carga do electrão

Relatividade para todos

PUBLICAÇ̃ O DE MAIS TRÊS PROGRAMAS: Primeiros programas para Windows
11. TABELA PERIÓDICA
12. LANÇA!
13. JOGO DAS COISAS

Tudo sobre os elementos

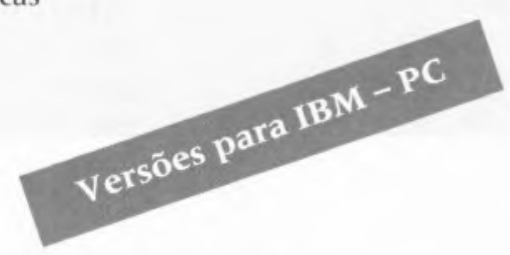

Projectáveis: Lançamento do dardo no computador

Jogos de fazer pensar (para todos os grupos disciplinares)

Vídeo: GALILEO e KEPLER (15 min em VHS)

Solicite já os seus programas para:

Softciências - SPF - Departamento de Física - Universidade de Coimbra - 3000 COIMBRA

Envie cheque no valor de $2500 \$ 00$ por cada programa com o respectivo manual (2000\$00 para Sócios da SPF, SPQ ou SPM) e $2000 \$ 00$ para o vídeo (1500\$00 para Sócios da SPF, SPQ ou SPM). O preço inclui os portes de correio. 